\title{
Belphégor
}

\section{La campaña social anticomic en la Gran Bretaña de postguerra}

\author{
Ignacio Fernández Sarasola
}

\section{(2) OpenEdition}

\section{Journals}

\section{Electronic version}

URL: http://journals.openedition.org/belphegor/798

DOI: 10.4000/belphegor.798

ISSN: 1499-7185

\section{Publisher}

LPCM

\section{Electronic reference}

Ignacio Fernández Sarasola, «La campaña social anticomic en la Gran Bretaña de postguerra », Belphégor [Online], 14 | 2016, Online since 07 October 2016, connection on 02 May 2019. URL : http:// journals.openedition.org/belphegor/798 ; DOI : 10.4000/belphegor.798

This text was automatically generated on 2 May 2019.

\section{(c) (i) () $\Theta$}

Belphégor est mis à disposition selon les termes de la Licence Creative Commons Attribution - Pas d'Utilisation Commerciale - Pas de Modification 4.0 International. 


\title{
La campaña social anticomic en la Gran Bretaña de postguerra
}

\author{
Ignacio Fernández Sarasola
}

\section{1.- Introducción}

1 Los años cuarenta y cincuenta fueron especialmente preocupantes para los cómics, a pesar de coincidir con su consolidación como género. Y es que, tan pronto empezaron a adquirir popularidad, fueron objeto de intensas campañas sociales dirigidas a desacreditarlos, imputándoles los más diversos perjuicios para la juventud y la infancia : desde ocasionarles daños a la vista (debido a la mala impresión y sus llamativos colores), hasta fomentar el analfabetismo, dificultar el proceso educativo de los niños, pervertirlos o, incluso, inducirles a la comisión de delitos. En este movimiento anticómic confluyeron los grupos más diversos: desde padres y madres hasta educadores, intelectuales, religiosos, bibliotecarios, sociólogos, psiquiatras y psicólogos.

2 Esta campaña tuvo su punto neurálgico en Estados Unidos, donde los cómics habían florecido como en ninguna otra latitud, pero se extendió como un reguero de pólvora (aunque con sus propias especificidades) por otros lares: no sólo por territorios próximos, como Canadá y México, sino incluso en la otra orilla del Atlántico, como en Gran Bretaña, Francia, Italia y España, por poner sólo algunos significativos ejemplos. La presión social llegó a ser tal, que en algunos casos acabó convenciendo a las autoridades sobre la necesidad de imponer medidas legislativas destinadas a controlar la venta de cómics. Y así se hizo, por ejemplo, en Estados Unidos, donde no existió normativa federal, pero sí un abundante legislación tanto estatal como municipal ; en Canadá, con la reforma del Código Penal promovida por el representante Davie Fulton en 1949; o en Francia, con la aprobación de la Loi n 49-956 du 16 juillet 1949 sur les publications destinées à la jeunesse.

3 Este fue también el caso de Gran Bretaña, donde la campaña social adquirió una enorme presencia, desencadenando que el Gobierno Churcill aprobase en 1955 una ley dirigida a controlar los cómics: la Children and Young Persons Act, más conocida como Harm Publications Act. Una ley que todavía hoy sigue en vigor, tras una prórroga sine die 
acordada en 1965. Pero, ¿en qué consistió exactamente esa campaña social tan influyente? ¿Qué grupos la orquestaron y qué medidas emplearon? Y, en definitiva, ¿cuáles eran sus reticencias a los cómics, y cuáles los móviles que la dirigían? A estos interrogantes trataremos de responder en las páginas siguientes.

\section{2.- La presencia del comic book estadounidense y los inicios de la campaña social}

4 Las tiras cómicas gozan en Gran Bretaña de una arraigada tradición que se remonta, al menos, a las revistas satíricas Punch (1841-1992), Fun (1861-1901) y Judy (1867-1907), pero que hallarían auténtico acomodo a través de la publicación semanal Ally Sloper's HalfHoliday (1884-1923), con una tirada que llegó a alcanzar los trescientos cincuenta mil ejemplares por número. En la década de 1890, Amalgamated Press aprovecharía el éxito de Ally Sloper's para editar nuevas revistas que obtuvieron una rápida popularidad, debido tanto a su calidad como a su bajo coste: Comic Cuts (1890-1953), Illustrated Chips (1890-1953) y Funny Wonder (1893-1953). En los años treinta del siglo XX irrumpieron con fuerza The Dandy (1937) y The Beano (1938), devoradas por una juventud que, además, tenía la costumbre de intercambiar sus lecturas, acrecentando así la difusión de los cómics.

5 Estas revistas, elaboradas por y para los británicos, abrazaron los más diversos géneros. Desde aventuras basadas en personajes del cine -Laurel y Hardy, en Film Fun (1920-1962), o Chalie Chaplin, en Funny Wonder (1893-1953)-, hasta los clásicos animales animados -con los populares Tiger Tim, Muffin the Mule y Rupert-, pasando, por supuesto, por el género de aventuras -donde destacó la revista Eagle (1950-1969)- y la ciencia-ficción (con el debut del popular personaje Dan-Dare).

6 Sin embargo, la hegemonía de los cómics británicos sufrió un declive tras la II Guerra Mundial. La presencia de cómics norteamericanos se hizo cada vez más notable, debido, en muy buena medida, a la circulación de aquellas revistas entre las tropas estadounidenses destinadas en el Reino Unido. Ante la perspectiva de negocio -en ambas orillas del Atlántico- Gran Bretaña comenzó a importar dichas publicaciones, haciéndose incluso con licencias que le permitían imprimirlas directamente, alcanzando tiradas superiores a los cincuenta mil ejemplares mensuales. Esta ofensiva cultural suscitó una inmediata reacción cívica en la que confluyeron estamentos muy dispares: desde activistas políticos hasta profesores, intelectuales, bibliotecarios, educadores, libreros y grupos religiosos ${ }^{1}$. Todos ellos parecían interpretar un mismo acorde: los cómics estadounidenses estaban inoculando entre la juventud e infancia un corrosivo veneno que debía erradicarse de inmediato.

7 Esta común percepción orientó el debate de toda la campaña anti-cómic, y sirvió para fijar a los ojos de la sociedad quién era el presunto enemigo que había que combatir, y cuál el objetivo que pretendía alcanzarse. Por lo que se refiere al primer extremo, las miradas críticas no apuntaron indiscriminadamente al género del cómic, sino a un espécimen concreto : el procedente de Estados Unidos. De hecho la campaña se centró en lo que empezaron a denominarse como "cómics de estilo americano" (American-style comics), caracterizados, al parecer de sus detractores, por su contenido violento, escabroso y sexualmente deplorable. Sólo a partir de 1953 empezó a relegarse el anterior concepto $^{2}$, sustituyéndolo por el de "horror comics", en un intento de no criminalizar a la nación norteamericana. Aun así, el nuevo término adoleció de igual imprecisión, puesto 
que en ese subgénero artístico no sólo se incluyeron -como sería propio- los cómics de terror, sino cualesquiera que presentasen un contenido obsceno, en un sentido amplio del término. En realidad, en Estados Unidos sucedió algo parecido, ya que en esa orilla del Atlántico se rechazaron ante todo los "crime comics", considerando como tales no ya a los de temática policial, criminal o detectivesca, sino cualesquiera que presentasen un contenido violento.

8 Por lo que se refiere al objetivo perseguido con la campaña "anti-cómic", parece claro que la tutela de los menores fue su principal línea argumentativa. Sin embargo, a este telón de fondo subyacían algunos intereses mucho más complejos y que no siempre se perciben a primera vista.

9 En efecto, el movimiento contra los cómics que se fue extendiendo en el Reino Unido a finales de los años cuarenta se amparaba principalmente en el interés por proteger a los menores de edad de la perversa influencia de unas lecturas que consideraba inapropiadas. En esta línea, se acusaba a esas revistas de ser depravantes, de obstaculizar el proceso educativo de la infancia y, en fin, de promover la delincuencia juvenil. Había, pues, un triple argumento: el moral, en el que incidirían sobre todo los grupos religiosos, el intelectual, en el que insistirían particularmente libreros, bibliotecarios y educadores, y, en fin, el de orden público, que preocupaba en especial, aunque no exclusivamente, a los políticos.

10 La necesaria protección de la infancia resultaba tanto más acuciante en un país devastado por la guerra y que depositaba sus esperanzas de reconstrucción en las generaciones futuras. Muchos de los niños de la posguerra habían sido testigos de las atrocidades del conflicto armado y vivían sus consecuencias, tanto sicológicas como materiales, por lo que se hallaban más necesitados de protección. No es casualidad que fuese precisamente en 1954 -coincidiendo con la efervescencia de la campaña anti-cómic- cuando vio la luz la inmortal obra de William Golding, Lord of the Flies, en la que se mostraba cómo, ante la ausencia de supervisión de los adultos, los niños revertían a un estado de naturaleza hobbesiano. En la obra de Golding, de indudable cariz filosófico, ya no se trataba de describir con un realismo literario las miserias que vivía la infancia -como había hecho Charles Dickens- sino de anticipar los males que podían derivarse de una falta de atención hacia los menores. De ahí que el Estado asumiese una inmediata tarea asistencial hacia los niños, perceptible en la Children Act (5 de Julio de 1948), aprobada un año antes de que concluyese la Segunda Guerra Mundial para tutelar a los menores de edad que careciesen de una "vida familiar normal".

11 La idea de que los cómics causaban un daño irreparable en las impresionables mentes de los menores de edad -argumento "moral"- fue una constante en la campaña británica "anti-cómic". El único tema de esas revistas, se decía, "es la violencia, lo brutal,

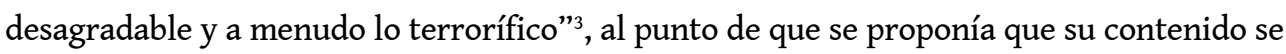
calificase, por esos mismos motivos, como obsceno y susceptible de persecución penal ${ }^{4}$. En realidad, esas mismas imágenes a las que se acusaba de degradantes traducían en términos gráficos truculencias no insólitas en la literatura británica : basta referirse a un autor tan emblemático en Inglaterra como Edgar Allan Poe, por no hablar de los conocidos como Penny Dreadfuls -que también habían suscitado una reacción a mediados del XIX al vinculárselos con la criminalidad juvenil- y las narraciones sobre terror $\mathrm{y}$ crímenes tan populares en la época victoriana, de las que es un buen ejemplo el anónimo Spring Heeled Jack: The Terror of London (1837). Así pues, la temática de los cómics se correspondía con una cultura de cierta tradición en el Reino Unido, y no puede dejar de 
señalarse incluso la proximidad temática entre la literatura anglosajona de los años cincuenta y los cómics que circulaban en esa misma década.

12 Aunque de forma más excepcional, también hubo alguna imputación de racismo al cómic estadounidense. La población negra solía retratarse como inferior y habitualmente adoptaba el papel de villana ${ }^{5}$. El argumento, sin embargo, no tuvo tanta fuerza en el Reino Unido como en Francia, donde, por ejemplo, Jean-Paul Sartre había cargado las tintas contra el popular personaje Tarzán, al que consideraba la personificación de un mesianismo caucásico.

13 Más atención se prestó en Gran Bretaña al contenido sexual de las imágenes presentes en los cómics. Si los grupos religiosos incidían en la amoralidad que exudaban los cómics, las fuerzas de izquierda ponían el acento en el tratamiento inadecuado que dichas revistas dispensaban a las mujeres, a las que retrataban con demasiada frecuencia casi desnudas, con posturas insinuantes, sometidas al héroe de turno $\mathrm{y}$, en definitiva, mostrándolas "como un ser inferior cuya única arma son sus curvas"6. El género de ciencia-ficción, que rápidamente se popularizó en Gran Bretaña merced a la tradición de autores de la talla de H. G. Wells, fue uno de los que más uso hizo de esas imágenes estereotipadas, a través de unas portadas que pretendían servir como reclamo al público masculino.

En realidad, el tratamiento de la mujer como objeto sexual no era patrimonio de los cómics estadounidenses. Uno de los más populares personajes británicos fue Jane (1932-1959), que, a través de sus andanzas publicadas en el Daily Mirror, protagonizaría la primera tira cómica "pinup". El autor de Jane, Norman Pett, había diseñado un personaje que pretendía atraer tanto al público femenino -por los modelos que lucía- como masculino -por la tendencia a desprender a Jane de esos mismos modelos-. De hecho, el personaje se hizo muy popular entre las fuerzas británicas combatientes en la II Guerra Mundial, momento en el que Jane llegó a ser retratada totalmente desnuda para animar a las tropas. De ahí que se atribuya a Churchill la afirmación de que Jane era "el arma secreta de los británicos"' Y, desde luego, tampoco la literatura británica se escapó en los años cincuenta de las acusaciones de amoralidad, como evidencia el caso de Ian Fleming, cuyo personaje James Bond (1952), nacido en plena campaña anti-cómic, recibió críticas por su apología del sexo y la violencia.

15 Pero fue en la vertiente intelectual y educativa donde la campaña empezó a organizarse a través de la creación del Comics Campaign Council, nacido en 1953 a partir de la London Federation of Parent-Teachers Association. Aquella asociación formulaba entre sus principios rectores el objetivo de desanimar la producción y venta de cómics de estilo americano, sustituyéndolos por lecturas más recomendables, que incluso podían -por qué noadoptar la forma de historietas. No debe desconocerse, de hecho, que algunos niños británicos desplazados de sus ciudades por los bombardeos alemanes se habían iniciado en la lectura gracias a los cómics, obras accesibles en tan penosa situación. Percibiendo su potencialidad, el clérigo Marcus Morris -fundador de la Society of Christian Publicity (1948)-, en colaboración con un oficial de la Royal Army Service Corps, Frank Hampson, creó una nueva revista de cómics genuinamente británica, Eagle, destinada a ser una alternativa educativa y saludable frente al modelo estadounidense de cómics. En este sentido, volvía a enfrentarse el producto nacional con el extranjero, ya que, según era común afirmar durante la campaña anticómic, si bien las antiguas historietas británicas habían contribuido a que muchos niños desarrollaran interés por la lectura, los cómics de "estilo americano" sólo eran una sucesión de imágenes coloreadas, en las que había desaparecido cualquier vestigio de letra impresa, a salvo de las continuas onomatopeyas 8 . 
Para sus críticos, los "American-style comics" resultaban, por tanto, la antítesis de cualquier pretensión educativa.

Aparte del referido defecto que se achacaba a la fórmula narrativa empleada por los cómics -y que supuestamente fomentaría el analfabetismo- algunos géneros fueron objeto de una especial inquina por considerarlos particularmente dañinos para la formación intelectual de los menores. Uno de los casos más emblemáticos fue el de los cómics de ciencia-ficción, que resultaron también catalogados primero como "Americanstyle comics" y, después, como "horror comics". En realidad, el género de ciencia-ficción gozaba de una notable popularidad entre los novelistas británicos. No sólo existían algunas relevantes revistas y autores dedicados a esta temática (como Olaf Stapledon), sino que incluso los literatos ajenos a ella la aprovechaban como instrumento de crítica sociopolítica, tal y como había sucedido con Aldous Huxley en los años treinta (Brave New World, 1932), con Orwell a finales de los cuarenta (1984, publicado en 1949) o con Anthony Burgess en la década de los sesenta (A clockwork orange, 1962). Por no mencionar a Kingsley Amis, universalmente conocido por su hilarante Lucky Jim (1954) y que en 1960 elaboraría una particular historia del género de la ciencia-ficción (New Maps of Hell).

Pero la campaña anti-comic no albergaba tan buena imagen de este género. Le imputaba el mostrar a los menores disparates físicos9. Nada que ver con el género de la anticipación científica, del que era tan representativo Jules Verne en Francia, y que hasta cierto punto cultivaría H. G. Wells en Gran Bretaña. De hecho, el propio George Orwell, que también había utilizado el género de la ciencia ficción en su distopía 1984, criticaría severamente los cómics de ese género, en los que "un sorprendente número de personajes tienen capacidad de volar" y que, en definitiva, no resultaban sino un compendio de "sensacionalismo sin sentido, sin nada del interés científico que desprenden las historias de H. G. Wells"10. Por si fuera poco, añadía Orwell, los cómics de ciencia ficción mostraban la cara más oscura de la ciencia, y como ejemplo se refería al desfile de profesores locos que construían bombas atómicas en laboratorios subterráneos ${ }^{11}$. ¿Cómo podían, pues, inculcar entre la juventud el amor por la lectura y la pasión por la ciencia?

18 El escaso valor educativo de los cómics "de estilo americano" vino respaldado por la crítica que sobre ellos habían vertido, además, algunos conocidos novelistas británicos. Como acabamos de ver, tal es el caso de George Orwell -ya desde su temprano ensayo Boys' Weeklies (1939) ${ }^{12}$ - pero también de Enid Blyton, autora, ésta última de un poema American Comics (and Those Like Them)- en la que rechazaba aquellas publicaciones. Algo especialmente paradigmático, proviniendo de una novelista que escribía para los niños y cuyas obras se consideraban una alternativa a la lectura de cómics.

Precisamente la búsqueda de productos más "educativos" fue una constante del movimiento cívico anticómic. El propio Orwell había señalado cómo los cómics salían perdiendo siempre en cualquier comparación que se hiciese con la literatura clásica destinada a la adolescencia: "La sociedad que se describe [en la literatura clásica] es contenida, ilustrada y casera; mientras que [la descrita en los cómics] muestra un mundo loco de bandidos, minas de oro, duelos, borracheras e infiernos de juego" ${ }^{13}$. Aun así, merece la pena señalar que Orwell afirmaba que, aunque nunca dejaría que un cómic cayera en manos de un niño, tampoco era partidario de prohibir su venta, ya que sentaría un peligroso precedente ${ }^{14}$. Sin duda, el mundo controlado por el Estado que él mismo había descrito en 1984 y en su fabulación política del stalinismo -Animal Farm (1945)pesaba en la mente del escritor británico. 
20 Pero quizás el argumento capital contra los cómics residió en la idea de que incentivaban la criminalidad entre los jóvenes. Todo ello en un clima de auténtica violencia juvenil, que alcanzaría uno de sus puntos álgidos en 1958, con las revueltas de adolescentes en Notting Hill que preocupó sobremanera a la intelectualidad británica, llegando a convertirse en el tema de la novela Absolute Beginners (1959), de Colin MacInnes.

21 La imputación a los cómics de fomentar las conductas criminales entre los menores de edad se aireó con especial intensidad a través de la prensa, con el destacado papel del Daily Dispatch durante el verano de 1954. De hecho, el pistoletazo de salida de la campaña anti-cómic puede situarse precisamente en la prensa, cuando el reverendo Marcus Morris empleó el Sunday Dispatch como púlpito para acusar a los cómics estadounidenses de incentivar la violencia y criminalidad juveniles ${ }^{15}$. Como haría Wertham en Estados Unidos, también en Gran Bretaña se trajeron a colación casos de delincuentes que habían reconocido ser lectores de cómics, sacando de ahí la conclusión -ya decidida de antemano- de que las lecturas eran al menos parcialmente responsables de la conducta delictual.

22 Huelga decir que no todos pensaban así, y hubo quien reivindicó el valor de los cómics para la iniciación a la lectura ${ }^{16}$, cuestionando la relación de causalidad que pretendía establecerse entre la comisión de delitos y el consumo de aquellas revistas ${ }^{17} . \mathrm{Y}$, desde luego, hubo un claro intento de diferenciar entre los cómics y las tiras cómicas publicadas en los periódicos ${ }^{18}$. Aun así, el argumento contra los cómics tenía mucha fuerza en una sociedad que padecía esos efectos de la delincuencia juvenil y que, por tanto, estaba predispuesta a hallar culpables. Eliminar los cómics de estilo americano se acabó convirtiendo, por tanto, no sólo en un asunto de tutela de los menores de edad, sino en una cuestión de orden público. La búsqueda por hallar un equilibrio entre la represión de la delincuencia juvenil y la tutela de los derechos subjetivos empezó entonces a plantearse como una preocupación de primer orden, que llegó incluso a trasladarse al ámbito literario con A clockwork orange (1962) de Anthony Burguess.

23 Pero, como ya se ha señalado, más allá del objetivo manifiesto -proteger la infanciahabía otros intereses en liza que también pesaron en la campaña anti-cómic. No es despreciable el valor que tuvo en este conflicto un cierto repliegue tradicionalista y nacionalista. Tras la II Guerra Mundial, el Reino Unido aspiraba a preservar sus señas de identidad frente a la invasión cultural que llegaba desde Estados Unidos de la mano del European Recovery Program. Por tal motivo llegó a verse en los cómics unas formas de cultura extrañas, algo que resultó común con la Francia de posguerra. A pesar de que Estados Unidos proporcionaba recursos financieros destinados a la reconstrucción, Gran Bretaña no deseaba perder lo que consideraba como sus genuinas manifestaciones culturales, entre las que se hallaban, desde luego, las tiras cómicas, pero que en nada se parecían a esa nueva forma artística proveniente de Estados Unidos.

24 En realidad, a este argumento de índole cultural subyacían algunas ideas que, debidamente contextualizadas, lo explican mejor. Por una parte, el repliegue nacionalista se mixturaba con una crítica elitista a los medios de comunicación de masas ${ }^{19}$. La defensa de una genuina literatura británica enmascaraba el rechazo hacia nuevas manifestaciones de la libertad de prensa que se consideraban como formas artísticas menores o a las que ni tan siquiera se las deseaba calificar como arte. Por otra parte, el argumento nacionalista se ligaba también a la ya referida defensa de los menores de edad, al considerar que para reconstruir Gran Bretaña tras la guerra era preciso educar a la 
juventud en los valores genuinamente británicos. Algo, por otra parte, que también se consideró en Francia por esas mismas fechas.

Junto a la intención de proteger la infancia, y de tutelar los valores nacionales, hay un tercer aspecto que explica la campaña anti-comic : el más específicamente político y, en concreto, la emergencia de un sentimiento antiamericano. De hecho, gran parte de la campaña contra los cómics estadounidenses (y sus respectivas versiones inglesas) fue orquestada por integrantes del Communist Party of Great Britain, interesados en promover el antiamericanismo. No en balde las primeras voces de alarma contra los cómics surgieron en Inglaterra de dos miembros de dicho partido político : el profesor de historia Peter Mauger, y el pediatra del Whittington Hospital, Simon Yudkin. Y en su campaña anticomic, el Partido Comunista no tuvo reparos en aliarse con otros grupos a veces poco afines -como el Comics Campaign Council, la Iglesia, y la National Union of Teachers- para forzar medidas legislativas contra el cómic estadounidense.

26 No puede desconocerse, sin embargo, que las maniobras del Partido Comunista en este sentido no fueron exclusivas del Reino Unido. También se manifestaron en Francia, donde además dicho partido empleó el argumento social de la defensa de los artistas galos, con el fin de impedir la importación de los cómics estadounidenses. En Gran Bretaña, sin embargo, el Partido Comunista se centró en destacar los valores negativos que, a su parecer, fomentaban los cómics estadounidenses y, muy en particular, la denigración política y racial que traían consigo. A tales efectos, aquel partido político denunció la imagen que los cómics proporcionaban de los comunistas, a los que siempre se retrataba como taimados enemigos dispuestos a desestabilizar el gobierno y a cometer para ello toda suerte de tropelías. Del mismo modo, se alzaron voces airadas contra la estereotipada forma en que los cómics estadounidenses representaban a la población de la República Popular de China, a la que hacían portadora de los más depravantes instintos. De forma descarada, las historias de ciencia ficción convertían a los malvados dictadores en personajes con rasgos asiáticos. Así sucedería tanto con Ming, en el caso de Flash Gordon como, apenas unos años antes, con los pérfidos Mongols en las aventuras de Buck Rogers.

27 Pero, según el Partido Comunista Británico, los cómics estadounidenses no se contentaban con criminalizar la ideología de izquierdas sino que, además, fomentaban un pensamiento fascista ${ }^{20}$. En este punto se trajo a colación al emblemático Superman. El culto a la fuerza como elemento de resolución de controversias, y la imagen misma de un superhombre, era para los comunistas el fiel reflejo de los principios nacionalsocialistas que habían combatido fervientemente durante la recién concluida Guerra Mundial, aparte de entrañar una apología de una "mentalidad de guerra" ${ }^{21}$. No podían, por tanto, admitir que entre la juventud se propagaran esos mismos valores que habían traído tantas calamidades a Europa.

28 El Partido Comunista, además, apeló al nacionalismo -tan a flor de piel en la convulsa postguerra- y condenó a los cómics por difundir el estilo de vida estadounidense, en un "imperialismo cultural" que estaba minando el "espíritu humanista y racionalista" británico. El culto al dinero, la opresión racial y la inclinación hacia la violencia eran enseñas del modus vivendi estadounidense que traslucían en los cómics. Era preciso levantar las barricadas e impedir esa invasión cultural, frenando la importación de aquellas revistas en las que se malgastaban fondos del plan Marshall ${ }^{22}$.

29 Curiosamente, en la otra orilla del Atlántico las interpretaciones de la campaña anticómic venían a tener una lectura bastante distinta. Y es que en Estados Unidos no faltó 
quien acusara a los cómics norteamericanos de fomentar valores comunistas, justo en el momento en el que el Maccartismo se hallaba en su apogeo.

En todo caso, el Partido Comunista hubo de maniobrar con cuidado, a fin de evitar que la campaña anti-comic se interpretara como una postura exclusivamente política, debilitando sus argumentos. De ahí que emplearan también un discurso pacifista y humanista, muy adecuado para una época que acababa de conocer el terror de la bomba de hidrógeno, detonada por vez primera en Eniwetok, el 1 de noviembre de 1952 y que, como bien decía Bertrand Russell, había convertido en nimio el miedo a las bombas de Hiroshima y Nagasaki. A ello había que añadir el nuevo clima de inestabilidad política y de desconfianza que generaba la guerra fría y, de resultas, el miedo a nuevos conflictos de alcance internacional que el Partido Comunista intentó explotar.

\section{3.- Dos destacados activistas de la campaña anti- cómic : Wagner y Pumphrey}

31 A pesar de cuanto acaba de mencionarse, lo cierto es que bastante a menudo los tres argumentos contra los cómics -el jurídico-moral, el cultural y el político- se entremezclaron. Algo especialmente evidente en Geoffrey Wagner y George Pumphrey; dos autores cuyo papel en la campaña anti-cómic merece un tratamiento aparte.

32 Coincidiendo con la aparición en Estados Unidos de la obra Seduction of the Innocent (1954), del psiquiatra Fredric Wertham, que marcaría el ritmo de la campaña anti-comic en Norteamérica, Geoffrey Wagner, publicaba en Londres una obra que seguía la misma pauta : Parade of Pleasure (1954). Geoffrey Atheling Wagner, era británico de nacimiento, aunque había adquirido la nacionalidad estadounidense tras emigrar a dicho país, donde trabajaría como Profesor de inglés en el City Collage de la City University of New York. En su Parade of Pleasure, Wagner elaboró una concienzuda crítica -no exenta de una pátina de elitismo- que alcanzaba a los principales símbolos iconográficos de Estados Unidos, como las películas, los cómics y las "pin-ups"; crítica que refleja perfectamente la imagen que muchos de los británicos guardaban de los cómics elaborados en Estados Unidos. A tales efectos, rastreó las que él consideraba como señas de identidad de algunas de las más populares temáticas de aquellas publicaciones : los superhéroes, las aventuras bélicas, el crimen y el terror. Un abanico temático que, según ya se ha anticipado, en Gran Bretaña se clasificó en un único tipo, denominado como "American-style comics", primero, y como "horror comics", desde 1953.

33 En síntesis, la postura de Wagner entrañaba una diatriba hacia los cómics desde un cuádruple prisma : el instructivo o educacional, el social o moral, el de orden público, y el político. Comenzando por el aspecto educativo, Wagner traía a colación el presunto efecto nocivo que la lectura de cómics representaba para los menores, tanto en su formación humanística como científica. Según su criterio, aquellas populares revistas, salpicadas por onomatopeyas y anémicas de texto, no sólo no fomentaban la lectura, sino que la obstaculizaban, creando una dependencia hacia la imagen que conducía indefectiblemente a forjar una sociedad analfabeta. En lo referente a la enseñanza de ciencias experimentales la situación no mejoraba. Por una parte, las aventuras de superhéroes y de ciencia ficción encadenaban disparates contrarios a las más elementales leyes de la naturaleza, amén de mostrar a los científicos ora como locos villanos, ora como 
ridículos personajes que constantemente requerían ser rescatados por el hipermusculado héroe de turno ${ }^{23}$.

De este modo, los cómics no sólo no aportaban nada a la formación intelectual del menor, sino que a la postre la perjudicaban, dificultando la tarea docente que asumían los centros educativos, las bibliotecas y las instituciones científicas. Es más, la interferencia resultaba todavía más acusada por el hecho de que la lectura de aquellas revistas era extremadamente absorbente para los niños, consumiendo mucho del tiempo que debían dedicar a tareas más productivas para su intelecto ${ }^{24}$.

35 Si estas críticas de carácter "educacional" pretendían proteger al menor en el desarrollo de su derecho a una educación adecuada, la vertiente moral y social de las críticas de Wagner tendía, además, a salvaguardar tanto a ciertas instituciones, como a grupos sociales determinados. En efecto, el escritor británico se rebeló contra la forma en que los cómics estadounidenses trataban a la familia y, más en particular, a la institución matrimonial a la que se presentaba siempre como una competición o un campo de batalla. Pero más preocupante era, si cabe, la imagen que esas publicaciones ofrecían de la mujer. Por una parte, por el modo de retratarlas físicamente, semidesnudas o en poses provocativas ; pero, por otra, las mujeres aparecían como víctimas de chistes machistas algo que se extendía incluso a las propias revistas destinadas a chicas adolescentes-, o como frágiles damiselas sometidas a la fuerza ${ }^{25}$. De este modo, se denigraba a la mujer, perpetuando una imagen de subordinación al varón. Desde esta perspectiva, los argumentos de Wagner trataban de dispensar protección no sólo a los menores -evitando que fuesen formados en valores socialmente reprensibles- sino también a las mujeres que devenían, así, víctimas indirectas de los controvertidos cómics.

36 El tercer ámbito en el que se centró Wagner fue el del orden público, tan habitual en la campaña anti-cómic. Sin embargo, el profesor británico evitó en la medida de lo posible incriminar a los cómics, y quedó al margen de la vidriosa polémica de si éstos guardaban relación con el incremento de delincuencia juvenil. Aun así, Wagner consideraba que la violencia que exudaban aquellas publicaciones acarreaba efectos nocivos para el Estado. En primer lugar, porque entrañaba un culto a la fuerza -en detrimento de la inteligenciay fomentaba la violencia física como única fórmula de resolución de conflictos, lo cual contribuía a generar un ambiente embrutecido, a la par que insensibilizaba a la sociedad. Por si fuera poco, el monopolio de coacción física en manos del Estado quedaba en entredicho por la figura de unos superhéroes que Wagner no dudaba en tildar de criminales, puesto que se sustraían al Estado de Derecho. Unos superhéroes, además, que aparecían como los únicos capaces de solventar la delincuencia, frente a las autoridades, siempre retratadas como ineficientes. Es más, incluso el ejército -máxima expresión de la fuerza física de un Estado- resultaba incorrectamente retratado en los cómics : aparte de servir de excusa para narraciones que tenían por objeto sólo la violencia, mostraban una vida castrense caracterizada por el individualismo, omitiendo algunos de sus auténticos rasgos de identidad, como la jerarquía, el orden y el trabajo en equipo ${ }^{26}$.

37 El último aspecto que Wagner consideraba reprensible de los cómics puede calificarse como político. En efecto, en su Parade of Pleasure, Wagner se sumaba al argumento esgrimido por el Partido Comunista Británico de que los cómics estadounidenses mostraban una clara inclinación hacia el fascismo. Siguiendo a Walter J. Ong, Wagner llegaba a denominar a Superman y Batman como "encarnaciones del Führer". Y, en la misma línea, apuntaba cómo los cómics norteamericanos denigraban al socialismo como 
opción política ${ }^{27}$, convirtiendo a los seguidores de esta ideología en pérfidos villanos a los que había que combatir.

38 Por su parte, George Pumphrey fue el más activo de los promotores de la campaña social anti-comic, al punto de que en alguna ocasión se ha equiparado su papel en Gran Bretaña al de Fredric Wertham en Estados Unidos ${ }^{28}$, considerándolo incluso más decisivo por su vocación moralizante ${ }^{29}$. Director de una escuela de educación primaria en el condado de Sussex, su primer acercamiento a los cómics -según él mismo relataba- había tenido lugar cuando buscaba material de lectura para los estudiantes. Fue entonces cuando se topó con un ejemplar de Eerie, un cómic del género de terror que había visto la luz en Estados Unidos en 1947, luego editado en Inglaterra en 1951. Pumphrey decía haber quedado horrorizado por el contenido de aquellas truculentas historias narradas a través de impactantes imágenes donde se sucedían hombres-lobo, muertos vivientes y asesinatos. A partir de entonces, el educador británico se enfrascó en una intensa labor de divulgación sobre los perjuicios que los cómics causaban en las débiles psiques de los menores. Así verían la luz sus tres obras más conocidas : Comics and your children (1954), Children's comics : a guide for parents and teachers (1955) y What children think of their comics (1964). La primera de ellas, además, serviría para dar publicidad a las actividades del Comics Campaign Council, en el que el propio Pumphrey había ingresado a través de la intermediación del doctor Simon Yudkin. Su papel en la campaña fue determinante para la adopción de medidas legislativas contra los cómics y, de hecho, un artículo suyo para el Times Educational Supplement (17 de septiembre de 1954) en el que sometía a juicio otra publicación de terror -Haunt of Fear- resultó decisiva para que el Gobierno de Churchill decidiese presentar el Harmful Publications Bill.

39 Quizás la característica más particular de Pumphrey fue el tono, al menos aparentemente, apolítico de sus argumentaciones, lo que le distanciaba de las posturas esgrimidas por los miembros del Communist Party of Great Britain, confiriéndole, a la par, una cierta imagen de neutralidad. Sin embargo, el punto de mira de ambos no estaba tan distante, puesto que tenían en común el nacionalismo, la seña de identidad de lo británico amenazada por la presencia de una forma cultural foránea. Así, Pumphrey, como los comunistas ingleses, enfocaba sus críticas ante todo hacia los cómics estadounidenses, dedicando apartados de sus textos a los que denominaba como "American type comics". Y cuando sus diatribas se dirigían hacia las revistas británicas, como Eagle, era por imitar lo que se editaba en la otra orilla del Atlántico. Una contaminación, pues, en toda regla, derivaba de la invasión cultural que había sufrido Gran Bretaña a través de la presencia de tropas estadounidenses -portadoras de los nocivos cómics procedentes de su propio país- y de la posterior importación de planchas y revistas excedentes ${ }^{30}$.

40 Como a otros muchos críticos, a Pumphrey no le agradaban los cómics ni en su forma ni en su contenido. Por lo que se refiere a la primera, consideraba que la combinación léxico-pictórica perjudicaba las habilidades lectoras de los niños, por cuanto éstos atendían en primer lugar a las imágenes y sólo después acudían al texto. Un texto, por otra parte, encorsetado en "globos" -un sistema poco ortodoxo, a su parecer- y redactado con rotundo desprecio hacia el lenguaje, como demostraba la presencia constante de americanismos. De ahí que los cómics conformasen una lectura residual, al punto de que sólo tendrían un valor -y muy relativo- en aquellos hogares en los que no se leía ninguna otra $\cos ^{31}$. Claramente, en las palabras de Pumphrey se entremezclaban dos argumentos : el nacionalista y el de rechazo hacia los medios de comunicación de masas. 
41 Tampoco el contenido de los cómics estadounidenses era del agrado de Pumphrey. Por supuesto, el género de terror era uno de sus blancos preferidos ; las truculentas imágenes que se podían visualizar en esas revistas implicaban un daño moral al menor, ocasionándole, además, pesadillas y desazón. La repugnancia de Pumphrey por el género de terror era lógica, puesto que su primer contacto negativo con los cómics había tenido lugar a través de la ya mencionada revista Eerie. Poco después, Pumprhey tendría ocasión de criticar abiertamente otra popular revista de terror, Haunt of Fear ${ }^{32}$, según ya se ha mencionado.

42 La violencia era también otra constante en los cómics, que la glorificaban a lo largo de sus escabrosas viñetas ${ }^{33}$. Los jóvenes lectores se sentirían, de este modo, identificados con los brutales protagonistas, lo cual los acabaría convirtiendo, a ellos mismos, en delincuentes. En este punto, Pumphrey se refería expresamente las conclusiones a las que se había llegado en la campaña anti-cómic de Estados Unidos, citando en particular tanto a Fredric Wertham como al Comité parlamentario constituido en Nueva York en marzo de 1949 para estudiar la relación de los cómics con la delincuencia juvenil. De hecho, el libro Seduction of the Innocent de Wertham se había presentado públicamente en Londres, en 1955, bajo la vitola de ser una lectura imprescindible para entender y paliar la delincuencia juvenil.

43 Pumphrey consideraba que no había género o personaje de cómic que quedase al margen del extremo nivel de brutalidad habitual en dichas revistas. Así, las mujeres aparecían retratadas con el mismo grado de sadismo que los hombres, aunque con el añadido de que se las representaba con poses y vestimentas provocativas. Desde su punto de vista, ambos elementos contribuían por igual a depreciar a las mujeres, estableciendo, además, una velada relación entre sexo y crueldad ${ }^{34}$. El género de superhéroes, por su parte, también mostraba un uso desmedido de la fuerza, evidente incluso en el modo en el que se retrataba siempre al "modelo Superman": sujeto cuyos hipertrofiados músculos se hallaban en relación inversamente proporcional al tamaño de su cabeza ${ }^{35}$. Es decir, la fuerza frente el cerebro ; un argumento en el que, por cierto, coincidiría con Jean Paul Sartre. Supermán y sus imitadores siempre se situaban por encima de la ley y resolvían por sus propios medios las controversias, de modo que el cómic estadounidense se convertía en una apología de un individualismo incompatible con el Estado de Derecho ${ }^{36}$.

44 Así las cosas, parece claro que para Pumphrey los cómics no podían servir como referente alguno para los niños. Ni les enseñaban conocimientos útiles, ni tampoco valores positivos. Bastaba ver el género de ciencia-ficción, donde sólo se mostraban disparates científicos -como ya había apuntado Orwell-, poco provechosos para el género humano, y en el que se describía al científico como un personaje desequilibrado. Respecto de la validez moral de los cómics, Pumphrey ponía como ejemplo el descarado racismo que exudaban, con un desprecio absoluto hacia los extranjeros.

45 Todo este afán de proteger a los menores de edad que latía en los escritos de Pumphrey se enmarcaba, sin embargo, en una imagen un tanto idealizada de la infancia y juventud. No sólo por imputar las malas conductas de los menores a influencias externas -como los cómics- sino por afirmar que, en realidad, los niños se veían compelidos a leer dichas revistas incluso cuando las denostaban De este modo, el consumo de cómics venía a asimilarse a la drogadicción : los niños, aun cuando sufrían pesadillas y veían con disgusto las viñetas, se veían incapaces de abandonar la rutina contraída. Sólo unos años más tarde el propio Pumphrey llegaría a reconocer que muy posiblemente los menores 
entrevistados habían respondido aquello que el encuestador quería oír, esto es, su disgusto con los cómics ${ }^{37}$.

Ello no impidió que este activo educador británico propusiese mecanismos para combatir a los cómics dejándolos, literalmente, fuera de circulación. Las medidas propuestas se dirigían principalmente a exigir la intervención de los poderes públicos: un estricto control de las importaciones, una aplicación eficaz de la Obscene Publications Act (en cuyo ámbito de aplicación, a su parecer, encajaban los cómics) y una pertinaz presión social sobre el legislador para que se decidiese a adoptar medidas normativas.

47 No transcurriría mucho tiempo antes de que esta última propuesta de Pumphrey mostrara su efectividad.

\section{4.- La repercusión de la campaña social en la actividad política}

Las voces críticas contra los cómics no tardaron en tornarse en un auténtico estado de alarma social, al punto de que en los años cincuenta dos de cada tres británicos parecían mostrarse a favor de prohibir ese género de literatura. A ello contribuyó la amplitud de la campaña social, de la que se hicieron eco incluso los Estados Unidos y que resultó hábilmente orquestada : prensa, radio, televisión, panfletos, libros, exposiciones... Todo un elenco de fórmulas al servicio de un mismo objetivo : frenar ese "veneno que se está extendiendo para contaminar las mentes de los niños británicos" ${ }^{38}$.

49 Como ya se ha visto, la prensa fue especialmente beligerante. A mediados de los años cincuenta, el influyente diario The Times puso de relieve la existencia de una opinión pública cada vez más contraria a los cómics de terror y a los valores que éstos inspiraban ${ }^{39}$ - Otros medios de comunicación, como la radio, tampoco se quedaron al margen, programando debates sobre el nocivo papel de los cómics. Por su parte, en las conclusiones elaboradas por un panel de expertos organizado por el Comics Campaign Council se propusieron medidas de impacto inmediato que abarcaban desde una campaña informativa dirigida a colegios, padres y hospitales, hasta la formación de grupos de estudio que publicasen boletines indicando qué lecturas eran nocivas. Unas respuestas sociales que debían complementarse con la participación activa de las empresas editoriales, formando un sello de calidad que debía ser supervisado por un Comité ciudadano de expertos de carácter permanente (es decir, un control social) que pretendía imitar al Cincinnati Committee for the Evaluation of Comics.

50 La propia campaña social anti-cómic no tardaría en considerar que estas propuestas resultaban insuficientes. Desde finales de 1954 y comienzos de 1955 ya eran numerosas las voces que reclamaban la actuación del Estado. Así, en febrero de este último año el periódico The Times señalaba la perentoria necesidad de aprobar una legislación restrictiva de los "horror comics" ${ }^{40}$ o al menos reformar la Obscene Publications Act para dar acogida expresa a aquellas revistas ${ }^{41}$. Ante todas estas medidas de presión, era sólo cuestión de tiempo que los poderes públicos decidiesen intervenir. Los hechos se precipitaron cuando a finales de 1954 el Comics Campaign Council remitió un proyecto de ley al Secretario del Interior, Gwilym Lloyd George. Y apenas unos meses antes, la National Union of Teachers había promovido una exposición sobre los cómics, a la que había asistido el Ministro de Educación, Sir David Eccles, y que poco después también se podía ver en la mismísima Cámara de los Comunes. 
51 Resulta evidente que esta campaña social contra los cómics orientó el debate que tuvo lugar en el Parlamento Británico no sólo entre los meses de Febrero y Abril de 1955 momento en el que se discutió el Harmful Publications Bill- sino incluso en los tres años anteriores. Basta ver tanto la terminología empleada (American-style comics, en un primer momento, y horror comics, más tarde) como la similitud existente entre las imputaciones que vertieron hacia dichas revistas los parlamentarios y las que se habían oído extramuros del Palacio de Westminster. De hecho, en 1952 ya se percibían voces en el Parlamento clamando por una ley anti-cómic, al considerar que la campaña social resultaba por sí sola insuficiente para erradicar ese supuesto mal que amenazaba a los niños británicos. Poniendo el acento en los cómics estadounidenses, como primera medida requirieron al Gobierno para que limitase las importaciones de aquellas revistas, si bien el Ejecutivo se negó a utilizar las aduanas como un mecanismo velado de censura.

$52 \mathrm{Y}$ es que, el Gobierno Churchill se mostró en un primer momento reticente a intervenir contra los cómics. Algo lógico en un país en el que la libertad de prensa había sido un basamento de su Estado de Derecho. Aun así, el incontenible avance de la campaña social hizo que pronto se decidiese a cambiar de parecer. En este sentido, el apoyo ofrecido a la compaña anti-comic por la National Federation of Retail Newsagents, Booksellers and Stationers ${ }^{42}$ resultaría de especial relevancia, por cuanto mostró la disposición de los propios vendedores a que se restringieran las transacciones sobre ese tipo de revistas.

En 1954, finalmente el Gobierno comenzó a poner en marcha la maquinaria estatal para restringir la venta de cómics. No cabe duda de que la campaña social fue la responsable de ese cambio de actitud: en un memorando presentado al Gobierno conjuntamente tres miembros del Ejecutivo (el Ministro de Educación, el Secretario del Interior, y el Secretario de Estado para Escocia) $)^{43}$, citaban expresamente la "fuerte presión" existente para que se aprobase una regulación legal de los cómics de terror y con contenido violento.

El resultado de la actividad gubernamental fue un proyecto legislativo que, tras un intenso debate parlamentario, se convertiría en 1955 en la Harmful Publications Act ( Children and Young Persons Act, 3 \& 4 Eliz. 2 Ch. 28). Una norma que prohibía -y aún lo hace- la impresión, venta o alquiler de revistas susceptibles de caer en manos de menores de edad y que consistiesen (total o parcialmente) en historias contadas a través de ilustraciones (o sea, cómics), cuyo contenido incluyese la comisión de delitos, actos de violencia y crueldad o incidentes de naturaleza repulsiva, todo ello con tendencia a corromper.

Era la respuesta del Estado británico a esa campaña social que había conseguido hacer el ruido suficiente como para promover una intervención legislativa.

\section{NOTES}

1. Cfr. Walker, John Albert: Cultural offensive: America's impact on British art since 1945, Pluto Press, London, 1998, p. 209. 
2. Barker, Martin: A Haunt of Fears: the Strange History of the British Horror Comics Campaign, University Press of Mississippi, Jackson, MS ; London, 1992, p. 18.

3. International Women's Day Committee: Lure of the "Comics", Farleigh Press Ltd., Watford, 1952, p. 3. Quisiera agradecer expresamente a Stephen O'Day, autor de la imprescindible web "Seduction of the Innocent" (http://www.lostsoti.org), dedicada a la campaña anti-cómic, la amabilidad al proporcionarme este texto de muy difícil acceso. Véase igualmente Pickard, Phyllis Marguerite: British comics: an appraisal, Comics Campaign Council, London, 1955, pp. 14-15.

4. Denning, Lord Alfred: The Road to Justice, Stevens \& Sons, London, 1955, p. 86.

5. Pickard, Phyllis Marguerite, British comics: an appraisal, op. cit.., p. 15.

6. International Women's Day Committee, Lure of the "Comics", op. cit., p. 5. No obstante, lo cierto es que esta misma publicación se quejaba de que los cómics describían a las mujeres "tan crueles como los hombres"; una crítica que, después de todo, llevaba implícita una idea preconcebida de la mujer. Sobre la depauperación de la mujer en los cómics, vid. igualmente Mauger, Peter: "Children's Reading", Arena, vol. 2, núm. 8 (Special Issue: The U.S.A. Threat to British Culture), 1951, p. 46.

7. Pett, Norman / Freeman, Donald: "Introducing Jane. Strip (tease) Heroine and Queen of the Undieworld", Pett, Norman / Freeman, Donald, The Misadventures of Jane, Titan, London, 2009.

8. International Women's Day Committee, Lure of the "Comics", op. cit., p. 6.

9. Locke, Simon: Re-crafting Rationalization. Enchanted Science and Mundane Mysteries, Ashgate Publishing Limited, Farnham, 2011, pp. 14-16.

10. Orwell, George: "Magic and Sadism", Leader Magazine (July 21, 1945).

11. Orwell, George: "Riding Down From Bangor", Tribune (November 22, 1946).

12. El texto puede consultarse en: http://orwell.ru/library/essays/boys/english/e_boys. Entre otras cosas, Orwell criticaba duramente el abuso de onomatopeyas en las tiras cómicas, que constituían por ello un canto al analfabetismo. Este escrito de Orwell se basaba principalmente en los cómics Gem y Magnet, a los que el escritor británico imputaba el intentar adoctrinar a los lectores en un ideario político conservador. Bounds, Philip: Orwell and Marxism : The Political and Cultural Thinking of George Orwell, I. B. Tauris, London, 2009, p. 68. El texto Boys' Weeklies' se ha considerado pionero de la posterior polémica. O'Flinn, J. P.: "Orwell on Literature and Society", College English, vol. 31, núm. 6, 1970, p. 610.

13. Orwell, George: "Riding Down From Bangor", Tribune (November 22, 1946), op. cit.

14. Orwell, George: "As I Please", Tribune (December 27, 1946).

15. Morris, Marcus: "Comics that bring Horror into the Nursery", Sunday Dispatch (February 1949), p. 3-5.

16. Avalado en algunos casos por estudios sobre la lectura de los cómics que proporcionaban una imagen bastante favorable de ellos. Así por ejemplo Thorndike, Robert L.: "Words and the Comics", The Journal of Experimental Education, vol. 10, núm. 2, 1941, p. 113, donde se concluía que los cómics empleaban un vocabulario extenso y que constituían una experiencia lectora con un nivel de dificultad propio de estudios de bachillerato. En el artículo Heisler, Florence: "A Comparison of Comic Book and Non-Comic Book Readers of the Elementary School", The Journal of Educational Research, vol. 40, núm. 6, 1947, p. 464, la conclusión de la autora era que la lectura de cómics carecía de efectos negativos para la capacidad lectora de los niños.

17. Pittman, David J.: "Mass Media and Juvenile Delinquency", Rouček, Joseph Slabey, Juvenile Delinquency, Philosophical Library, New York, 1958, pp. 230-250; Bailyn, Lotte: "Mass media and children: A study of exposure habits and cognitive effects", Mass media and children: A study of exposure habits and cognitive effects, vol. 73, núm. 1, 1959, p. 37.

18. Hadfield, John: "The Funnies", The Sunday Times (12-12-1954), p. 5. Anónimo: "The Comic Strip in American Life: A British View", The Times Literary Supplement (17-09-1954). Lo he consultado en: White, David Manning / Abel, Robert H.: The Funnies. An American Idiom, The Free Press of Glencoe / Collier-Macmillan Ltd., London, 1963, pp. 81-87. 
19. De hecho, el principal estudioso de la campaña anti-cómic, Martin Barker, ha incidido en la importancia de este factor, respecto a trabajos anteriores en los que atendía sustancialmente a condicionantes políticos. En este punto, señala que los cómics se rechazaban también por su "falta de gusto literario". Barker, Martin: "Getting a Conviction: Or, How the British Horror Comics Campaign Only Just Succeeded", Lent, John A., Pulp Demons. International Dimensions of the Postwar Anti-Comics Campaign, Associated University Press, Cranbury, 1999, pp. 77-79.

20. Mauger, Peter: "Children's Reading", op. cit.op. cit., pp. 45-46.

21. Ibídem, pp. 45-46; International Women's Day Committee, Lure of the "Comics", op. cit., p. 5.

22. Aaromvitch, Sam: "The American Threat to British Culture", Arena, vol. 2, núm. 8 (Special Issue: The U.S.A. Threat to British Culture), 1951, en especial pp.4-5, 6-9, 13 y 16-18; Mauger, Peter: "Children's Reading", op. cit., p. 45; Mauger, Peter: "The Cult of Violence Persists", Picture Post (20-11-1954), p. 17.

23. Wagner, Geoffrey: Parade of Pleasure. A Study of Popular Iconography in the U.S.A., Library Publishers, New York, 1955, pp. 103, 90, 88, 89.

24. Ibid., p. 71.

25. Ibid., pp. 75-101.

26. Ibid., p. 78-93 y 106.

27. Ibid., pp. 85-91.

28. Saraceni, Mario: The Language of Comics, Routledge, New York, 2003, p. 2.

29. Caputo, Tullio: Law and Society: A Critical Perspective, Harcourt Brace, Toronto, 1989, p. 151. De hecho, Pumprhey, lejos de centrarse tanto como Wertham en la hipotética relación causal entre cómics y delincuencia juvenil, hacía más hincapié en el término elaborado por este último de "desarme moral" de la infancia. Vid. a este respecto el comentario de Pumphrey a la obra de Wertham: Pumphrey, George Henry: "Britons Face the Same Dilemma. The Comics and «Moral Disarmament»", The Educatioin Digest, vol. 20, 1954, pp. 23 y ss.

30. Pumphrey, George Henry: Comics and your Children, Comics Campaign Council, London, 1955, pp. $5,8,16$.

31. Ibid., p. 5, 18.

32. Pumphrey, George Henry: "Carta de G. H. Pumphrey", Times Educational Supplement (17-09-1954).

33. Pumphrey, George Henry, Comics and your Children, op. cit., p. 19.

34. Idem. En realidad en este punto Pumphrey no resultaba muy coherente. La descarada sensualidad de las mujeres de los cómics contribuía, desde luego, a convertirlas en objetos sexuales. Sin embargo, la violencia que se les atribuía era equiparable a la de los varones y, en este punto, no había discriminación alguna. De hecho, ésta sí que se habría visto agudizada en el caso de que a la mujer, aparte de sensual, se la retratase con un rol sumiso.

35. Pumphrey, George Henry: Children's Comics. A guide for parents and teachers, Epworth Press, London, 1955, p. 6.

36. Pumphrey, George Henry, Comics and your Children, op. cit., p. 19.

37. Pumphrey, George Henry: What Children think of their comics, The Epworth Press, London, 1964, p. 7.

38. International Women's Day Committee, Lure of the "Comics", op. cit., p. 4.

39. "Horror Comics Campaign", en The Times (12 noviembre 1954); "New Horror Comics", The Times (24 de noviembre de 1955). El periódico también realizó un seguimiento de la campaña de Wertham en Estados Unidos, y la situación del cómic en aquel país.

40. The Times (22-02-1955).

41. The Sunday Times (19-12-1954), p. 11.

42. Holbrook, David: Creativity and Popular Culture, Associated University Press, Cranbury, 1994, p. 22. Dicha Federación llegó a dirigirse al Gobierno solicitando medidas restrictivas contra los 
cómics; petición que trajo consigo una pregunta parlamentaria, en el mismo sentido, del diputado George Oliver, House of Commons (18-11-1954), vol. 533, col. 548.

43. Horror Comics. Memorandum by the Secretary of State for the Home Department, the Secretary of State for Scotland and the Minister of Education (25 th November 1954), Secret C. (54) 359. The National Archives (CAB/129/72). En la defensa del proyecto de ley, Gwiliym Lloyd George alabó la tarea de la National Union of Teachers y llegó a asumir la imposibilidad de que los padres y educadores pudieran erradicar, por sí solos y sin medidas legislativas, el problema de los cómics. House of Commons (22-02-1955), vol. 537, col. 1072.

INDEX

Mots-clés: comic book, Gran Bretaña, littérature jeunesse

\section{AUTHOR}

\section{IGNACIO FERNÁNDEZ SARASOLA}

Universidad de Oviedo (Spain) 